\title{
Erratum to: Halloysite nanotubes as sustainable nanofiller for paper consolidation and protection
}

Giuseppe Cavallaro • Giuseppe Lazzara •

Stefana Milioto · Filippo Parisi

Published online: 29 August 2014

(c) Akadémiai Kiadó, Budapest, Hungary 2014

Erratum to: J Therm Anal Calorim

DOI 10.1007/s10973-014-3865-5

In the experimental section the sentence:

"Halloysite nanotubes $\left(\mathrm{Al}_{2} \mathrm{Si}_{2} \mathrm{O}_{5}(\mathrm{OH})_{4} \cdot 2 \mathrm{H}_{2} \mathrm{O}, \mathrm{HNTs}\right)$ are a gift from Applied Materials inc."

should be changed to:

"Halloysite nanotubes $\left(\mathrm{Al}_{2} \mathrm{Si}_{2} \mathrm{O}_{5}(\mathrm{OH})_{4} \cdot 2 \mathrm{H}_{2} \mathrm{O}, \mathrm{HNTs}\right)$ are a gift from Applied Minerals Inc."

The online version of the original article can be found under doi:10.1007/s10973-014-3865-5.

G. Cavallaro · G. Lazzara $(\bowtie) \cdot S$. Milioto · F. Parisi

Department of Physics and Chemistry, Università degli Studi di Palermo, Viale delle Scienze, pad. 17, 90128 Palermo, Italy

e-mail: g.lazzara@unipa.it; giuseppe.lazzara@unipa.it 